\title{
Social involvement in rural areas. A methodological approach
}

\author{
José M. Díaz-Puente ${ }^{1}$, Francisco J. Gallego ${ }^{2}$, Pablo Vidueira ${ }^{1}$ \\ ${ }^{1}$ Agricultural Engineering School, Polytechnic University of Madrid. Avenida Complutense \\ S/N, 28040 Madrid, Spain. \{jm.diazpuente@, pvm@alumnos.\}upm.es \\ ${ }^{2}$ Institute of Community Development of Cuenca. Calle Segóbriga, 7, 16001, Cuenca, \\ Spain.fgallego@idccuenca.org
}

\begin{abstract}
Community development must be accompanied by a social involvement process which creates functional groups of citizens capable of taking responsibility for their own development. It is important that this process promotes a structure for all population groups and provides the appropriate institutional and technical support. The present paper addresses these issues from a methodological approach based on over 25 years of experience by the Institute of Community Development of Cuenca in revitalizing rural areas of the Spanish province of Cuenca. The long-term perspective of this experience provides some keys which can be used to successfully support the process of social involvement in rural areas.
\end{abstract}

Keywords: Community development, Social Involvement, Social Structure, Partnership.

\section{Introduction}

Efforts to streamline the network of associations began with community organization. This concept is understood as a process where the community strives to control its problems and reach solutions through its organizations and institutions [23]. Therefore, the existence of organized groups of individuals acting together is essential [37], as well as the role of external actors in collaborating with the community throughout this process [30].

This role for the community depends on the existence of functional citizens' groups that promote individual participation, as well as the community's ability to be an active and responsible agent in the development process [43]. That is why the social involvement process is so essential and must always play a key role in the process of community development. The goal is to open channels for participation through which individuals can identify and prioritize their needs, and to encourage the work for supporting the development of the community [32], [20].

However, the presence of this boost to encourage participation does not guarantee that a genuine process of community development will take place [18]. The process of revitalization should be inclusive with all population groups. Numerous studies show 
the failure of development processes that only include certain groups of people [18], [35], [39], [6], [38], [22].

Similarly, it is crucial to the success of this process that the community is provided with the appropriate technical support [2] and with the support of public institutions [43], [2], [9], throughout the process of identification and prioritization of needs, as well as in creating development measures and in the analysis of resource availability.

Since the late nineties, within the framework of the LEADER Initiative, there has been a lot of research carried out regarding the changing role of public institutions and the processes targeting rural development [11], [29], [42], [46], [40], [19], [8]. The gradual democratization of developed countries has led to a change in the perception of development from traditional top-down approaches (welfare) to bottomup approaches, based on the direct use of national resources [44], [33], [10]. This change is essential for the viability of social structuring process [26], [7], and also has allowed to non-state organizations — which have the ability to mobilize local potential [10] — to take on a very important role as community partners in the development process. This role is especially important in terms of the organization within society [35], [25], [12] and even more so in areas with low population density, which can be characterized by intense isolation and rural exodus [38]. The contribution made by these associations is needed in order to achieve a more inclusive and participatory form of development [39], [22]. Public institutions need to trust that these associations and local actors are able to carry out proper management of the development process [26].

This article focuses on the social involvement model implemented by the Institute of Community Development of Cuenca (hereafter IDC Cuenca) during over 25 years in underpopulated rural areas. Based on this long term perspective, the article discusses a model founded on social inclusion and the promotion of participation by all sectors of the population by providing encouragement and support, prioritizing its most pressing needs, and seeking innovative responses to these needs. It will also seek to provide solutions with regard to the relationship between public institutions and local associations and the role played by these associations in the development process. This issue is crucial in determining the effectiveness of development programmes. It concerns individuals, partnerships and policy makers alike [2], [3].

\section{Context}

\subsection{Institutional Context: The IDC of Cuenca}

The IDC of Cuenca is a non-profit association founded in 1984 with the intention of promoting community development in depressed rural areas within the province of Cuenca, Spain. For over 25 years, it has been working to achieve three main objectives. Its first objective is to upgrade human resources and the structure of society in order to encourage a process of development within a framework of equality that improves quality of life and avoids further depopulation of rural 
communities. Its second objective is to preserve and enhance the regional identity, rural culture and natural resources. Finally, the association attempts to build on current innovation and quality practices in agriculture and promote entrepreneurship through the incorporation of new techniques and technologies.

These objectives are achieved through a methodology founded on ensuring access to information, improving training opportunities and encouraging the creation of a dynamic body of actors. The IDC seeks to encourage the development of these processes through promotional strategies, a thorough knowledge of the reality of the situation within the region and the formation of links within the population. After 25 years, this methodology has been shown to be capable of responding both to the needs as perceived by the local population and the more specific and urgent needs of the development process, reconciling the two with the initial context of each individual community. Thus, the IDC has established itself as an association for the development of far-reaching growth within the territory and, as discussed below, has spearheaded numerous development processes within the Cuenca province.

\subsection{Regional Background: The province of Cuenca}

The province of Cuenca is located in Spain, in the the central-eastern area of the country. The province covers $17,141 \mathrm{~km}^{2}$ [14] and has 217,363 inhabitants [16]. The population density of the province is 12.68 inhabitants per $\mathrm{km}^{2}$ [16], well below the national average of 90.6 inhabitants per $\mathrm{km}^{2}$ [17] and the European Union average of 113.5 inhabitants per $\mathrm{km}^{2}$ [17]. Of the 238 municipalities within the province, almost $80 \%$ (186 municipalities) have a population density of less than 10 inhabitants per $\mathrm{km}^{2}$, and 111 municipalities have less than 4 persons per $\mathrm{km}^{2}$ [15]. Currently, the majority of the province is suffering the effects of depopulation, as demonstrated by the loss of 34,208 inhabitants (13\%) since 1970 [13], and it is classified as a disadvantaged area at risk of depopulation by the Spanish Agricultural White Paper [27].

The area is characterized by a marked trend towards the predominance of agriculture, lack of training and service offerings, communication deficiencies -initially relating to poor road infrastructure and currently linked to deficits in information technology and communications- and social dislocation. IDC Cuenca is working to reverse these trends. In some cases, however, they continue to drive individuals away from the area.

These trends were reflected in Spain's Sustainable Rural Development Program for 2010-2014 (regulated by Law 45/2007), in which three of the five regions of Cuenca are among the rural areas identified as development targets due to low population density, the predominance of agricultural activity, low income levels, the significant extent of its geographic isolation and the difficulties of regional restructuring. The two remaining regions are classified as intermediate rural areas, which are areas that have low to medium population density, diversified employment, low to medium income levels and are geographically remote from major urban centers [28]. 


\section{Methodology of the social development process}

The IDC has promoted Cuenca over the course of the past 25 years, implementing a process of community development in its less populated rural areas and expending much of its effort in revitalizing the network of local associations and creating partnerships. This has primarily occurred in the form of locating and securing the cooperation of agencies and public and private entities in promoting the idea of development through potential synergies between endogenous and exogenous growth in the area [7]. This dynamic process, spearheaded by the IDC, has a number of distinctive features and methods. It is precisely these methods that have allowed this process to be ongoing today after 25 years.

Among these methods is the concept of social involvement as a process [36], [5] which begins as a set of successive and coherent phases. Another significant feature is the initiation of an established self-identity [31], [1] which seeks to unite the local population through an appreciation of its region, reinforcing their involvement in the development process once it begins. The third methodological feature of this process is the establishment of links between the association and the local population. Finally, this process places a strong emphasis on the analysis of social involvement and community development experiences in other areas. These can serve as the basis for the design of operational partnership models.

In addition to these methods, the IDC's work in the field of social involvement employs two main tools. The first is promotion, encouraging people to get involved in the process and, consequently, in their transformation into agents of change and growth within their own region [4]. The second is the accompaniment of this process with technical assistance in resolving all of the existing needs in the region through training, planning methodologies and tools, and providing an accountability framework for the implementation, monitoring and evaluation of initiatives [8].

Driven by promotional activities, a series of operational models to guide the structure and functioning of these associations have been designed. These models should be flexible in order to respond to the situation and the needs identified by the local population.

The social development process begins by channeling the established needs of the population through tailored operative models. These early experiences will be deemed successful if they manage to address the needs expressed by the population. To this end, the IDC provides support in the form of technical assistance and collaboration with its local associations. Positive results are used as a source of inspiration and motivation for groups not yet firmly rooted in the social structuring process. This encourages the population to continue its development process. Responding to their needs through partnership projects leads to an improvement in social structure and provides increased stimulation for other groups. Figure 1 outlines the methodology of the social involvement process implemented by the IDC over the course of the past 25 years. 


\section{IDC main features}

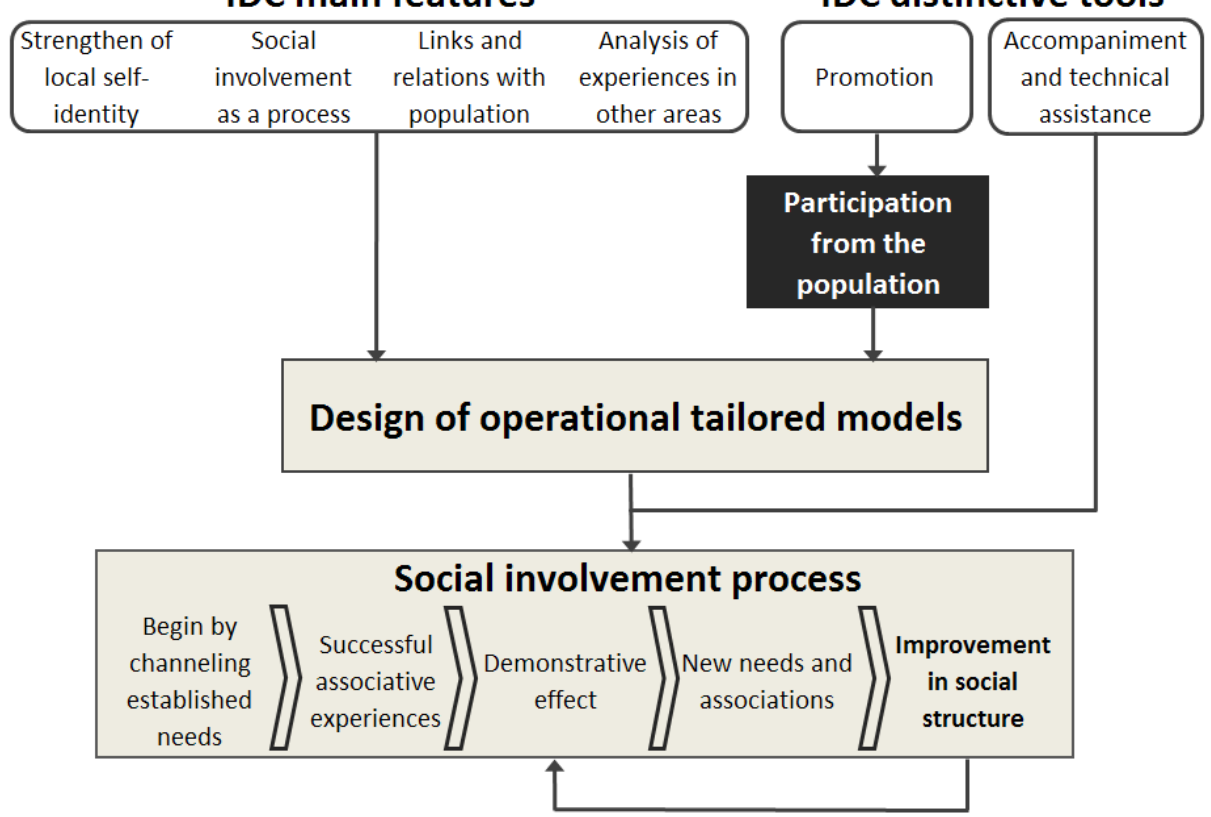

Fig. 1. Methodology of social involvement process implemented by the IDC of Cuenca.

\section{Conclusions}

Social development is one of the strongest guarantees for the progression of any development program [41] and is particularly important in areas with low population density. The model analyzed in this paper begins by encouraging people, in this case through the endogenous culture, and prompting them to unite because of their appreciation of the region and their interest in improving their living conditions. This methodological factor has also facilitated the entry of the IDC into the region in a way which is close to the population. The cooperative work created ties and mutual understanding between the IDC and local population.

The elements that act as stimuli are usually outside the community. In addition to culture, there are other factors such as perceived threats to their interests [2], the positive stimulus of an external agent [30] or the demonstration effect. The demonstration effect — when a group is organized and plunged into the development process and becomes a stimulus for other groups in the territory - is deeply rooted in rural areas and is essential in the social involvement process.

Another important methodological aspect is to have a defined working philosophy and the ability to adapt to the various initiatives that will be carried out. This can be seen throughout the work of the IDC although the cultural caravan is a prime example of something that was not proposed directly by the IDC Cuenca, but rather the 
provincial council under agreement with the IDC. However, the IDC learned to apply their principles to the activities in order to achieve the results shown above.

However, the community must have a full sense of ownership over the development process [2]. Therefore, it is necessary that the community is involved in determining those who actually require immediate help, rather than relying on the perspective of an external agent that will identify those who appear most urgent. Addressing the needs felt by the population unites individuals in achieving these goals. Actions to address needs not generating consensus results in division between those who agree and those who do not. Shared experiences adapted to the prioritised needs of the population should be based on flexible models which can provide innovative responses to those needs within their own specific context. In addition to the experience of the IDC Cuenca, it is clear that the response to these perceived needs will reveal new ones which encourage the continuation of the community development process [34].

Finally, the IDC's technical assistance and aid for associations emerging in the territory is of crucial importance. One aspect of this assistance targets the achievement, through partnerships, of plans that will provide content for the process and act as a force for greater cohesion among its members. Ongoing educational programmes, designed to strengthen awareness of the local situation and provide the population with new skills that promote social participation and develop leaders for the new development processes, are also crucial in this regard.

The process of social structuring encouraged by the Cuenca IDC has followed a specific guideline: associations arise as a consequence of the desire and will of their members to contribute to the achievement of certain objectives within their community. In this context, the role of the IDC is to encourage and facilitate this process through its tools and methodological characteristics. The role of this process of social activism is to promote social structure and enable people to address various aspects of their development according to their own needs [2]. This development becomes sustainable when the associations generate it themselves by forming new partnerships that continue to deepen through increased structuring of their society and additional improvements in the quality of life of their region's population.

\section{Bibliography}

1. Andolina, R., Radcliffe, S., Laurie, N.: Development and culture: Transnational identity making in Bolivia. Polit. Geogr. 24, 678--702 (2005)

2. Armstrong, J.: Making Community Involvement in Urban Regeneration Happen - Lessons from the United Kingdom. Community Dev. J. 28, 355--361 (1993)

3. Borek, T., Falkowski, J., Giejbowicz, E., Janiak, K., Poslednik, A. Zielin, Ska, M.: Inicjatywa doswiadczenia LEADER +-i pierwsze Rozwoju Szansa. Fundacja dla pomocy Programow Rolnictwa, Warszawa (2006).

4. Caride, J.A.: La animación sociocultural y el desarrollo comunitario como educación social. Revista de Educación 336, 73--88 (2005)

5. Clark, D., Southern, R., Beer, J.: Rural governance, community empowerment and the new institutionalism: a Case Study of the Isle of Wight. J. Rural Stud. 23, 254--266 (2007) 
6. Considine, M.: Local Partnerships: Different Histories, Common Challenges - a synthesis. In OECD, (Ed.). Managing Decentralisation: a New Role for Labour Market Policy,Organisation for Economic Co-operation and Development, Paris. (2003)

7. Díaz-Puente, J.M, Yagüe, J.L, Afonso, A.: Building Evaluation Capacity in Spain: a case study of Rural Development and empowerment in the European Union. Evaluation Rew. 32, 478--506 (2008)

8. Díaz-Puente, J.M, Cazorla, A., de los Rios, I.: Empowering Communities Through Evaluation: some lessons from rural Spain. Community Dev. J. 44, 53--67 (2009)

9. Edwards, B., Goodwin, M., Pemberton, S., Woods, M.: Partnerships, power, and scale in rural governance. Environ. Plann. C. 19, 289--310 (2001)

10. Furmankiewicz, M., Thomson, N., Zielinska, M., 2010. Area-based partnerships in rural Poland: the post-accession experience. J. Rural Stud. 26, pp. 52-62.

11. Goodwin, M., 1998. The Governance of Rural Areas: Some Emerging Research Issues and Agendas. J. Rural Stud. 14, pp. 5-12.

12. Grochowski, M., Regulska, J.: New partnership and Collaboration: Local Government and Its Supporting Institutions - The case of Poland. In: Amna, E. and Montin, S., (Eds.) Towards a New Concept of Local Self-government? Recent Local Government Legislation in Comparative Perspective, Fagbokforlaget, Bergen (2000)

13. Instituto Nacional de http://www.ine.es/inebaseweb/treeNavigation.do?tn=92693\&tns=141136 \# 141136

14. Instituto Nacional de Estadística, http://www.ine.es/jaxi/tabla.do?path=/t43/a011/a1998/10/\&file=t10031.px\&type=pcaxis

15. Instituto Nacional de Estadística, http://www.ine.es/jaxi/tabla.do?path=/t43/a011/a1998/densidad/10/\&file=t10051.px\&type= pcaxis $\& \mathrm{~L}=0$

16. Instituto Nacional de Estadística, http://www.ine.es/jaxi/tabla.do?path=/t20/e260/a2009/10/ $\&$ file $=$ pcaxis mun16.px \& type $=\& L=0$

17. Instituto Nacional de Estadística, http://www.ine.es/prodyser/pubweb/espcif/terr10.pdf

18. Jessop, B.: The dynamics of partnership and governance failure. In: Stoker, G., (Ed.), 1999. The New Politics of Local Governance in Britain, Oxford University Press, Oxford (1999)

19. Jones, O., Little, J.: Rural Challenges (s): partnership and new rural governance. J. Rural Stud. 16, 171--183 (2000)

20. Klsnerman, N.: Comunidad. Humanitas, Buenos Aires (1986)

21. Kovach, I.: LEADER, a new social order, and the Central and East-European countries. Sociol. Ruralis. 40, 181--189 (2000)

22. Katona Kovacs, J., Fieldsend, AF, Alderson, M., Szabo, G.: Human Factors and Social Factors stimulating endogenous growth as the LEADER Programme in Hungary. In: Florianczyk, Z. and Czapiewski, K. L., (Eds.), Stimulating Factors Endogenous Rural Development, Rural Areas and Development (vol. 4), National Research Institute, Institute of Geography and Spatial Organization, Polish Academy of Sciences, Warsaw (2006)

23. Lindeman, E.: The Community. An introduction to the study of community leadership and organization. Association Press, New York (1921)

24. Lowndes, V., Sullivan, H.: Like a horse and carriage or a fish on a bicycle: how well do local partnerships and public participation go together? Local Gov. Stud. 30, 51--73 (2004)

25. Hudson, R.: New geographies and forms of work and Unemployment and public policy innovation in Europe. Tijdschr. Econ. Soc. Ge. 93, 316--335 (2002)

26. MacKinnon, D.: Rural local governance and Involvement: Assessing state - community relations in the Scottish Highlands . J. Rural Stud. 18, 307--324 (2002)

27. Ministerio de Agricultura, Pesca y Alimentación: El Libro Blanco de la Agricultura y el Medio Ambiente(Vol. 3, cap.4.8). Spanish Ministry of Agriculture, Fisheries and Food, Spain (2003) 
28. Ministerio de Medio Ambiente, Rural y Marino, http://www.mapa.es/es/desarrollo/pags/Ley/ley.htm .

29. Murdoch, J., and Abram, S.: Defining the limits of community governance. J. Rural Stud. $14,41--50$ (1998)

30. Pettit, W.: Some Prognostications in the Field of Community Work. In National Conference of Social Work at the Fifty-second Annual Session Held in Denver, Colorado. University of Chicago Press, Chicago (1925)

31. Preston, R., and Arthur, L.: Knowledge societies and planetary cultures: The Changing Nature of consultancy in human development. International Journal of Education. 17, 312 (1997)

32. Porzecanski, T.: Desarrollo de comunidades y subculturas. Humanitas, Buenos Aires (1983)

33. Ray, C.: Neo-endogenous rural development in the EU. In: Cloke, P., Marsden, T. and Mooney, P. (Eds.). Handbook of Rural Studies, Sage, London (2005)

34. Rezsohazy, R., 1988. El desarrollo comunitario. Narcea, Madrid.

35. Rhodes, R.: The new governance: Governing Without Government. Political Studies. 44, 652--667 (1996)

36. Roseland, M.: Sustainable community development: Integrating Environmental, Economic, and Social Objectives. Prog. Plann. 54, 73--132 (2000)

37. Sanderson, D., Polson, A.: Rural community organization. John Wiley \& Sons, New York (1939)

38. Schejtman, A., Berdegué, J.: Desarrollo territorial rural. Debates y Temas Rurales. 1, 7--46 (2004)

39. Shucksmith, M.: Endogenous Development, social capital and social inclusion: perspectives from LEADER in the UK. Sociol. Ruralis. 40, 208--218 (2000)

40. Storey, D.: Issues of integration, participation and empowerment in rural development: the case of LEADER in the Republic of Ireland. J. Rural Stud. 15, 307--315 (1999)

41. Unión de Centros de Animación Rural. Rev. Renov. Rural. 21, 31--32 (1991)

42. Ward, N., McNicholas, K.. Reconfiguring Rural Development in the UK: Objective $5 b$ and the new rural governance. J. Rural Stud. 14, 27-39 (1998)

43. Ware, C.: Estudio de la Comunidad. Unión Panamericana, Washington DC (1949)

44. Westholm, E.: Exploring the role of rural partnership. In: Westholm, E., Moseley, M. and Stenlas, N., (Eds.). Local Partnerships and Rural Development in Europe: a Literature Review of Practice and Theory, Dalarna Research Institute, Falun (1999)

45. Williams, C.C.: Harnessing social capital: some lessons from rural England. Local Government Studies. 29, 75--90 (2003)

46. Woods, M.: Advocating rurality? Changing the position of rural local government. J. Rural Stud. 14, 13--26 (1998) 